\title{
ANALISIS POTENSI RISIKO UMKM DI KABUPATEN KUDUS
}

\author{
Mia Ajeng Alifiana \\ Universitas Muria Kudus \\ Email: mia.ajeng@umk.ac.id \\ Nanik Susanti \\ Universitas Muria Kudus \\ Email: susanti@umk.ac.id
}

\begin{abstract}
ABSTRAK
Kecamatan Undaan merupakan salah satu kecamatan di Kabupaten Kudus, dengan tiang penyangga utama dari perekonomian masyarakat terletak pada sektor industri. Beberapa hasil produk unggulan yang terdapat pada industri kecil dan kerajinan rumah tangga di Kecamatan Undaan diantaranya, ukiran kayu jati antik, gebyok, mebeler, konveksi, bordir, tenun ikat, gerabah, keset, aneka roti, kwaci, aneka kerupuk dan lain-lain. Namun, industri kecil dan kerajinan rumah tangga tersebut belum secara optimal dikembangkan. Pembinaan dan pengembangan UMKM yang tepat sasaran dapat dilakukan berdasar potensi risiko yang dimiliki. Untuk mengatasi kesenjangan tersebut, dilakukan penelitian untuk dapat menganalisis potensi risiko UMKM, agar dapat dilakukan pembinaan dan pengembangan UMKM yang lebih efektif dan tepat sasaran, sehingga UMKM dapat lebih berdaya saing. Metode penelitian dilakukan dengan 1) menggolongkan potensi risiko UMKM; 2) memberi peringkat dan predikat faktor potensi risiko UMKM; 3) menetapkan peringkat komposit potensi risiko UMKM. Ketiga langkah tersebut dilakukan berdasar potensi risiko UMKM dari aspek permodalan, produksi, dan pemasaran. Hasil penelitian menyatakan bahwa di Kecamatan Undaan Kabupaten Kudus, 1) berdasar 3 aspek penelitian, hanya terdapat 1 UMKM yang berpotensi risiko tinggi yakni di aspek permodalan.; 2) berdasar penetapan peringkat komposit potensi risiko UMKM terdapat 5 UMKM yang mempunyai potensi risiko rendah, dan 4 UMKM mempunyai potensi risiko sedang. Atas hasil penelitian tersebut, maka Disnakerperinkop dan UKM Kabupaten Kudus, terutama Kecamatan Undaan diharapkan dapat melakukan pengembangan dan pembinaan dengan lebih tepat sasaran, sehingga UMKM di Kecamatan Undaan dapat lebih berdaya saing.
\end{abstract}

Kata Kunci: Risiko, UMKM, Permodalan, Produksi, Pemasaran 


\begin{abstract}
Undaan Sub-district is one of the sub-districts in Kudus Regency, with the main pillar of the community economy located in the industrial sector. Some of the superior products that are found in small industries and home handicrafts in Undaan District are antique teak carving, gebyok, meubeler, convection, embroidery, ikat, pottery, mat, various bread, kwaci, various crackers and others. However, small industries and household handicrafts have not been optimally developed. Development of targeted SMEs can be done based on the potential risk. To overcome this gap, a research is conducted to analyze the potential risks of SMEs, in order to be able to do more effective and targeted development of SMEs, so that SMEs can be more competitive. The research method is conducted by 1) classifying the potential risk of SMEs; 2) rating and predicate potential risk factors for SMEs; 3) establish a composite rating of potential risks of SMEs. These three steps are conducted based on the potential risks of SMEs from capital, production and marketing aspects. The result of research stated that in Undaan District of Kudus Regency, 1) Based on 3 aspects of research, there is only 1 SME with high risk potency that is in capital aspect; 2) Based on the composite rating of the potential risks of SMEs there are 5 SMEs that have low risk potential, and 4 SMEs have medium risk potential. Based on the result of the research, Disnakerperinkop and UKM of Kudus Regency, especially Undaan Subdistrict are expected to develop with more target, so that SMEs in Undaan Subdistrict can be more competitive.
\end{abstract}

Key words: Risk, SMEs, Capital, Production, Marketing

\title{
PENDAHULUAN
}

Kecamatan Undaan merupakan salah satu kecamatan di Kabupaten Kudus, yang tiang penyanga utama dari perekonomian masyarakatnya terletak pada sektor industri. Beberapa hasil produk unggulan yang terdapat pada industri kecil dan kerajinan rumah tangga di Kecamatan Undaan diantaranya, ukiran kayu jati antik, gebyok, mebeler, konveksi, bordir, tenun ikat, gerabah, keset, aneka roti, kwaci, aneka kerupuk dan lain-lain. Namun, industri kecil dan kerajinan rumah tangga tersebut belum secara optimal dikembangkan. Pembinaan dan pengembangan UMKM yang tepat sasaran dapat dilakukan berdasar potensi risiko yang dimiliki.

Untuk mengatasi kesenjangan tersebut, dilakukan penelitian untuk dapat menganalisis potensi risiko UMKM, agar dapat dilakukan pembinaan dan pengembangan UMKM yang lebih efektif dan tepat sasaran, sehingga UMKM dapat lebih berdaya saing. Dengan UMKM yang berdaya saing tersebut dapat 
mendukung terwujudnya visi misi Pemerintah Kabupaten Kudus, terutama Kecamatan Undaan yang memiliki visi "Terwujudnya Penyelenggaraan Pemerintahan Umum dan Pelayanan Masyarakat yang Baik (Good Governance and Good Public Services)" dengan misi sbb.: 1) meningkatkan pemberdayaan ekonomi dan sosial masyarakat; 2) meningkatkan ketentraman, ketertiban, perlindungan dan kehidupan berpolitik masyarakat; 3) meningkatkan penyelenggaraan pemerintahan di tingkat kecamatan dan desa; 4) meningkatkan pelayanan administrasi publik.

Analisis potensi risiko UMKM di Kecamatan Undaan, Kabupaten Kudus, dilakukan terpatas pada aspek permodalan, produksi dan pemasaran. Penelitian ini dilakukan untuk membantu Disnakerperinkop dan UKM Kabupaten Kudus, terutama Kecamatan Undaan, maupun para pengabdi masyarakat lainnya, dalam melakukan pengembangan dan pembinaan terhadap UMKM di Kecamatan Undaan secara tepat berdasar potensi risikonya.

\section{TINJAUAN PUSTAKA}

\section{Usaha Mikro Kecil Dan Menengah}

Kementerian Negara Koperasi dan Usaha Kecil Menengah (Menegkop dan UKM), mendefinisikan Usaha Kecil (UK) termasuk Usaha Mikro (UMI) sebagai entitas usaha dengan kekayaan bersih paling banyak Rp200.000.000,- tidak termasuk tanah dan bangunan tempat usaha, dan memiliki penjualan tahunan paling banyak Rp1.000.000.000,-. Sementara Usaha Menengah (UM) merupakan entitas usaha milik Warga Negara Indonesia yang memiliki kekayaan bersih lebih dari Rp200.000.000,- sd. Rp10.000.000.000,- tidak termasuk tanah dan bangunan.

Badan Pusat Statistik (BPS) memberikan pengertian UKM berdasarkan jumlah tenaga kerja. Usaha Kecil adalah entitas usaha yang memiliki jumlah tenaga kerja 5 s.d 19 orang, sedangkan Usaha Menengah adalah entitas usaha yang memiliki tenaga kerja 20 s.d 99 orang. Berdasarkan Keputusan Menteri Keuangan Nomor 316/KMK.016/1994 tgl. 27 Juni 1994, Usaha Kecil adalah perorangan atau badan usaha yang telah melakukan kegiatan atau usaha yang mempunyai penjualan atau omset per tahun setinggi-tingginya Rp. 600.000.000,atau aset atau aktiva setinggi-tingginya Rp600.000.000,- di luar tanah dan bangunan yang ditempati, terdiri dari: a) Bidang usaha (Fa, CV, PT dan Koperasi); b) Perorangan (pengerajin/ industri rumah tangga, petani, peternak, nelayan, perambah hutan, penambang, pedagang barang dan jasa).

Kriteria UMKM menurut UU No. 20 Tahun 2008, berdasarkan jumlah aset dan omset yang dimiliki oleh sebuah usaha, seperti yang tampak pada tabel 1 . 
Tabel 1. Kriteria UMKM

\begin{tabular}{|l|l|l|l|}
\hline \multirow{2}{*}{ No. } & \multirow{2}{*}{ Usaha } & \multicolumn{2}{|c|}{ Kriteria } \\
\cline { 3 - 4 } & & Aset & Omset \\
\hline 1 & Usaha Mikro & Maks. Rp50 juta & Maks. Rp300 juta \\
\hline 2 & Usaha Kecil & >Rp50 juta - Rp500 juta & >Rp300 juta -2,5 miliar \\
\hline 3 & Usaha Menengah & $>$ Rp500 juta - Rp10 miliar & >Rp2,5 miliar - Rp50 miiar \\
\hline
\end{tabular}

Perkembangan jumlah UMKM menurut sektor ekonomi tahun 2012-2013 menurut Kementerian Koperasi dan UKM, adalah seperti yang tampak di tabel 2.

Tabel 2. Perkembangan Jumlah UMKM

\begin{tabular}{|l|l|r|r|}
\hline Keterangan & Satuan & Tahun 2012 & Tahun 2013 \\
\hline Usaha Mikro (UMi) & Unit & 55.856 .176 & 57.189 .393 \\
\hline Usaha Kecil (UK) & Unit & 629.418 & 654.222 \\
\hline UsahaMenengah (UM) & Unit & 48.997 & 52.106 \\
\hline Jumlah UMKM & Unit & 56.534 .592 & 57.895 .721 \\
\hline
\end{tabular}

\section{Risiko Dan Manajemen Risiko}

Dua kata yang dipakai untuk menggambarkan pengertian risiko dalam kosakata Bahasa Inggris, adalah hazard dan risk. Hazard merupakan potensi yang dapat menimbulkan keuntungan atau kerugian. Namun, dalam keseharian hazard identik dengan potensi yang menimbulkan kerugian. Risk adalah kemungkinan keuntungan atau kerugian yang muncul akibat paparan terhadap hazard, cenderung ke sisi negatif. (Sumber: A Guidance To Risk Management and Safety Engineering "Manajemen dan Teknik Penanganan Risiko).

Faktor yang mempengaruhi tinggi rendahnya suatu risiko adalah a) frekuensi terjadinya risiko; b) besar kecilnya kerugian yang mungkin terjadi; c) karakteristik daripada risiko itu sendiri. (Sumber: Jakarta Insurance Institute, 1993).

Pentingnya pengelolaan risiko dapat dilihat melalui bagan berikut ini:

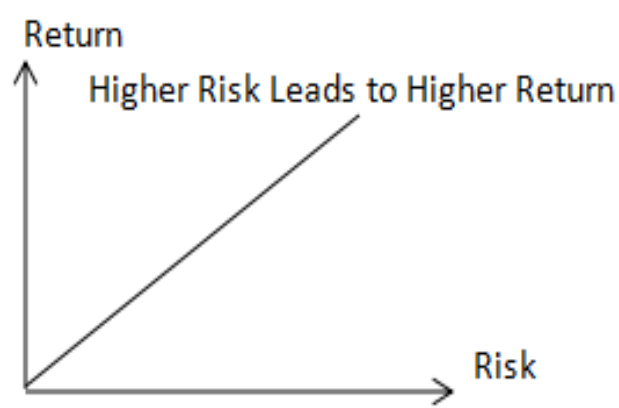

Pandangan Lama:

Semakin tinggi risiko, semakin tinggi tingkat keuntungan. (Sumber: Mamduh, 2006)

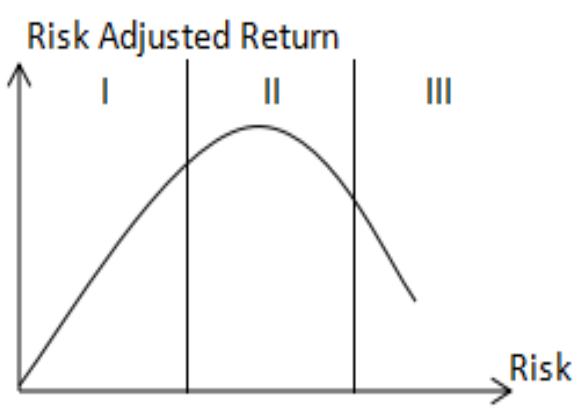

Pandangan Baru:

Risiko Harus dikelola

\section{Gambar 1. Hubungan Risk dan Return}


Enterprise Risk Management (ERM) adalah pengintegrasian dari a) organisasi dengan risiko yang terintegrasi, b) strategi risk transfer, dan c) manajemen risiko ke dalam proses bisnis perusahaan.

Dua proses kegiatan yang terlibat dalam pengintegrasian dari manajemen risiko ke dalam proses bisnis perusahaan adalah penilaian risiko (risk assessment) dan mitigasi risiko (risk mitigation), dimana keduanya saling ketergantungan dan saling melengkapi demi tercapainya tujuan memperkecil risiko.

Komponen penting di dalam risk assessment untuk merumuskan suatu risiko yang mungkin diahadapi suatu sistem atau sering disebut dengan level risiko, adalah a) karakteristik, b) ancaman, c) kelemahan sistem, d) kontrol, dan e) dampak dari terjadinya gangguan terhadap sistem.

Risk mitigation adalah proses untuk menindaklanjuti data, temuan dan rekomendasi dari proses risk assessment, yang terdiri dari a) proses penyusunan prioritas risiko, b) pemilihan kontrol yang sesuai, dan c) pengimplementasian kontrol (Tjahjo Adiprabowo, 2013).

\section{Publikasi Penelitian Ilmiah Sebelumnya}

a. "Analisis Faktor-Faktor Risiko Tertanggung Perusahaan Asuransi Kerugian (Studi Pada PT Asuransi Rama Satria Wibawa)" dalam tesis tahun 2008, oleh Mia Ajeng Alifiana, SE., MBA. dengan hasil faktor physical condition, neighbour condition dan cleanness condition dapat digunakan untuk menganalisis risiko tertanggung PT Asuransi Rama Satria Wibawa.

b. Publikasi di Universitas Gunadarma, 2012: "Analisis Potensi \& Hambatan Yang Dihadapi UMKM Dalam Mengembangkan Usaha Dengan Menggunakan Alat Bantu Sistem Informasi Geografis (SIG): Studi Kasus Kecamatan Pancoran Mas Kota Depok" oleh Hendry Milano Trenggana, Masodah, dan Edi Minaji Pribadi, dengan hasil utama dari aspek modal, produksi, dan pemasaran untuk menggambarkan kondisi sebagian besar UMKM di Kecamatan Pancoran Mas Kota Depok.

c. Jurnal BENEFIT: Jurnal Manajemen dan Bisnis, Vol. 16, No.2, Tahun 2012, Universitas Muhammadiyah Surakarta: "Manajemen Risiko Bisnis UMKM Di Kota Surakarta” oleh M. Farid Wajdi, Anton Agus Setyawan, Syamsudin dan Muzakar Isa, yang dilakukan berdasar risiko bencana, dengan aspek bisnis terpenting yang terkena bencana adalah 1) alat produksi, 2) tempat produksi, 3) permodalan, 4) hasil produksi. Dan alternatif tindakan antisipasi bencana: 1) menyisihkan sebagian penghasilan untuk berjaga-jaga $40 \%$, 2) menyusun prosedur standar kerja yang aman $35 \%, 3$ ) kerjasama dengan pihak lain 15\%,4) membeli polis asuransi 5\%, 5) lainnya $5 \%$. 


\section{METODE PENELITIAN}

Diagram alir proses penelitian sesuai dengan tujuan penelitian untuk mengetahui potensi risiko UMKM di Kecamatan Undaan, Kabupaten Kudus, adalah sebagai berikut:

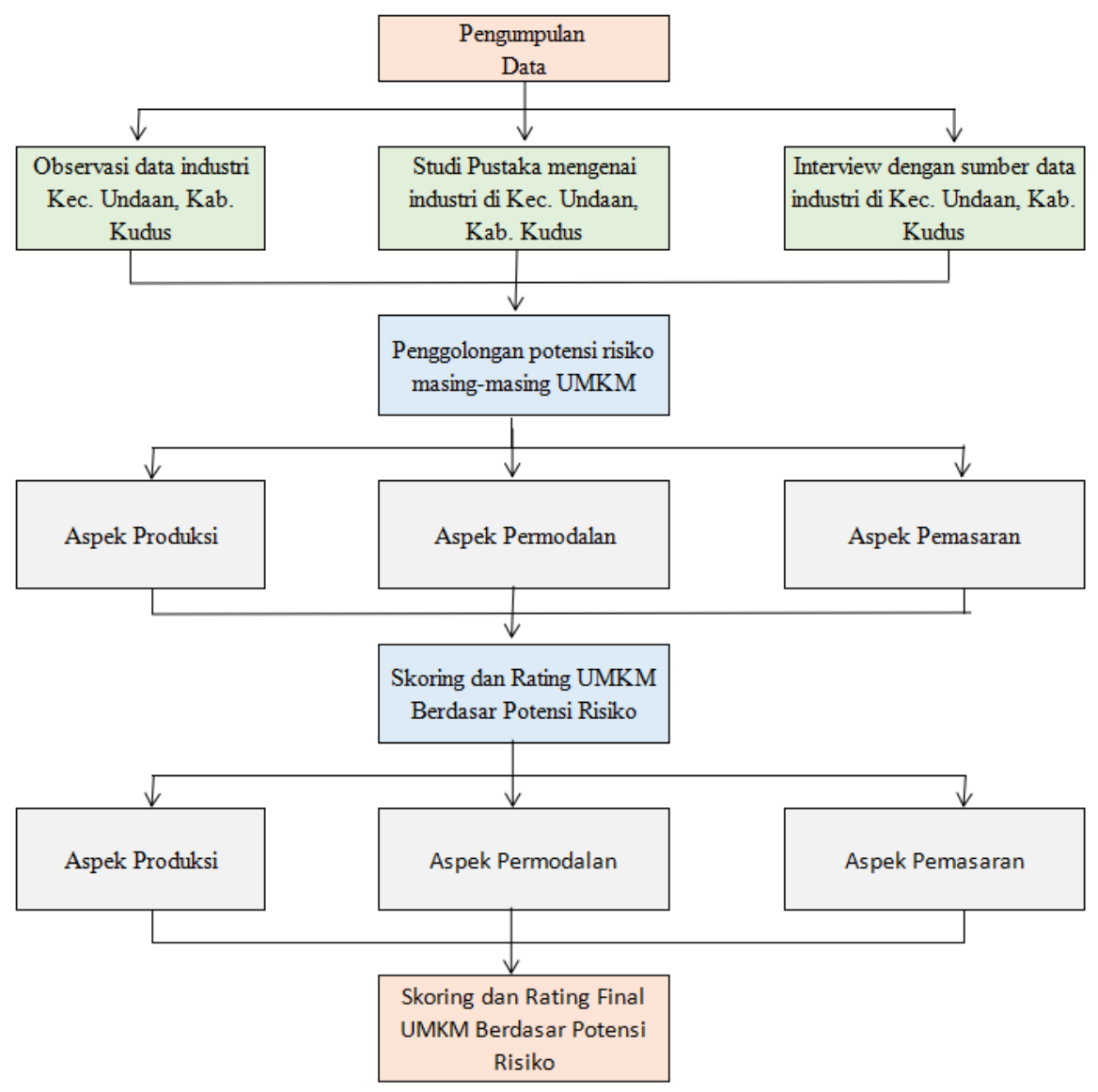

Gambar 2. Bagan Alir Penelitian

Teknik pengumpulan data dalam penelitian ini adalah melalui observasi, dan interview langsung dengan UMKM di Kecamatan Undaan, serta studi pustaka melalui literatur dan jurnal mengenai potensi risiko UMKM.

Objek penelitian ini adalah semua UMKM segmen kecil dan menengah di Kecamatan Undaan, Kabupaten Kudus, yang datanya diperoleh dari Dinas Tenaga Kerja Perindustrian Koperasi \& UKM Kabupaten Kudus, dan kemudian dilakukan verifikasi dan observasi ke lapangan atas keberadaannya, untuk dilakukan pengumpulan data potensi risiko terkait dengan aspek produksi, permodalan, dan pemasaran.

Analisis data dilakukan melalui 3 (tiga) tahapan, yaitu:

1. Penggolongan potensi risiko masing-masing UMKM, 
2. Penentuan peringkat dan predikat faktor UMKM berdasar potensi risiko yang dimiliki masing-masing aspek yang menjadi variabel penelitian,

3. Penetapan peringkat komposit potensi risiko UMKM berdasar potensi risiko dari aspek permodalan, produksi dan pemasaran.

Teknik analisis tersebut di atas seperti yang tampak pada gambar 3 di bawah ini:

\begin{tabular}{|c|c|c|}
\hline & (2) Penentuan Perin & Predikat Faktor Potensi Risiko UMKM \\
\hline & Poten & Dari Aspek Permodalan \\
\hline & Risiko Rendah : Modal & \\
\hline & Risiko Sedang : Modal & Dan Hutang Non Lembaga Keuangan \\
\hline & Risiko Tinggi : Hutang & ga Keuangan \\
\hline & Pote & co Dari Aspek Produksi \\
\hline (1) Penggolongan & Risiko Rendah : Peroleh & an Baku Lokal \\
\hline Potensi Risiko UMKM & Proses & i Manual \\
\hline - Rendah & Risiko Sedang : Peroleh & an Baku Lokal \& Non Lokal \\
\hline - Sedang & Proses & i Manual \& Teknikal \\
\hline - Tinggi & Risiko Tinggi : Peroleh & an Baku Non Lokal \\
\hline & Proses & i Teknikal \\
\hline & Poten & Dari Aspek Pemasaran \\
\hline & Risiko Rendah : Pemas & line \\
\hline & Risiko Sedang : Pemas & oungan Offline \& Online \\
\hline & Risiko Tinggi : Pemas & ine \\
\hline & (3) Penetapan Peringka & sit Potensi Risiko UMKM \\
\hline & Potensi Risiko Rendah: & $\begin{array}{l}\text { Total Skor } \leq 1 \text {, untuk aspek permodalan, } \\
\text { produksi, dan pemasaran. }\end{array}$ \\
\hline & Potensi Risiko Sedang: & $\begin{array}{l}\text { Total Skor } \leq 2 \text {, untuk aspek permodalan, } \\
\text { produksi, dan pemasaran. }\end{array}$ \\
\hline & Potensi Risiko Tinggi: & $\begin{array}{l}\text { Total Skor } \leq 3 \text {, untuk aspek permodalan, } \\
\text { produksi, dan pemasaran. }\end{array}$ \\
\hline
\end{tabular}

\section{Gambar 3: Teknik Analisis Data Penelitian}

\section{HASIL DAN PEMBAHASAN}

\section{Objek Penelitian}

Objek penelitian ini adalah UMKM di Kabupaten Kudus terbatas di 1 kecamatan, yaitu Kecamatan Undaan untuk segmen kecil dan menengah, yang datanya diperoleh dari Disnakerperinkop dan UKM Kabupaten Kudus, yakni terdapat 27 UMKM, yang terdiri dari 25 UMKM segmen kecil dan 2 UMKM segmen menengah. Dari 27 UMKM tersebut yang keberadaannya terverifikasi dan mempunyai kelengkapan data diperoleh 8 UMKM segmen kecil dan 1 UMKM segmen menengah, yang dapat dianalisis potensi risikonya berdasar aspek permodalan, produksi dan pemasaran. 


\section{Penggolongan Potensi Risiko UMKM}

Penggolongan potensi risiko UMKM segmen kecil dan menengah di Kecamatan Undaan, Kabupaten Kudus, berdasar objek penelitian di atas berdasar aspek permodalan, produksi dan pemasaran, dibagi menjadi 3 (tiga) yaitu: a) potensi risiko rendah, b) potensi risiko sedang, dan c) potensi risiko tinggi.

Rincian penggolongan potensi risiko UMKM berdasar aspek permodalan, produksi dan pemasaran adalah sbb.:

a) Aspek Permodalan:

1) Potensi risiko rendah jika sumber modal $100 \%$ adalah modal sendiri;

2) Potensi risiko sedang jika sumber modal terdiri dari modal sendiri dan hutang non lembaga keuangan;

3) Potensi risiko tinggi jika sumber modal 100\% dari hutang lembaga keuangan.

b) Aspek Produksi:

1) Potensi risiko rendah jika bahan baku diperoleh dari lokal (Kudus dan sekitarnya), serta proses produksi dilakukan secara manual;

2) Potensi risiko sedang jika bahan baku diperoleh dari lokal dan lokal (baik dari Kudus dan sekitarnya maupun dari luar Kudus), serta proses produksi dilakukan secara manual dan teknikal;

3) Potensi risiko

c) Aspek Pemasaran:

1) Potensi risiko rendah jika pemasaran dilakukan secara offline;

2) Potensi risiko sedang jika pemasaran dilakukan gabungan secara offline dan online;

3) Potensi risiko tinggi jika pemasaran dilakukan secara online.

\section{Peringkat dan Predikat Faktor Potensi Risiko UMKM}

Kriteria penetapan peringkat dan predikat faktor berdasar objek penelitian dilakukan dengan mengkuantifikasi data kualitatif potensi risiko UMKM berdasar aspek permodalan, produksi, dan pemasaran, dengan hasil sebagai berikut:

Tabel 4. Kriteria Penetapan Peringkat dan Faktor Objek Penelitian

\begin{tabular}{|r|l|r|r|r|}
\hline No & Nama Usaha & Permodalan & Produksi & Pemasaran \\
\hline 1 & MEBEL SUPARNO & 1 & 2 & 1 \\
2 & PERTOKOAN & 1 & 2 & 2 \\
3 & WARUNG KOPI SUMATNI & 1 & 1 & 1 \\
4 & TOKO JAJANAN & 1 & 1 & 1 \\
5 & KOPI KUMIATI & 1 & 1 & 1 \\
6 & TOKO PERTANIAN ABDULLAH & 1 & 2 & 1 \\
7 & JAHIT TAS INDAH & 3 & 1 & 1 \\
8 & BENGKEL MOTOR ABUT & 1 & 2 & 1 \\
9 & TOKO KUSNO PRANOTO & 1 & 1 & 1 \\
\hline
\end{tabular}


Keterangan: $1=$ berpotensi risiko rendah

$2=$ berpotensi risiko sedang

$3=$ berpotensi risiko tinggi

Dari tabel 3 tersebut di atas, diperoleh kesimpulan atas objek penelitian sebagai berikut.:

a) Berdasar aspek permodalan, terdapat 8 UMKM yang berpotensi risiko rendah, dan hanya 1 UMKM yang berpotensi risiko tinggi.

b) Berdasar aspek produksi, terdapat 5 UMKM yang berpotensi risiko rendah, dan 4 UMKM yang berpotensi risiko sedang.

c) Berdasar aspek pemasaran, terdapat 8 UMKM yang berpotensi risiko rendah dan hanya 1 UMKM yang berpotensi risiko sedang.

Dari hasil penetapan peringkat dan predikat faktor pada tabel 3 di atas tampak bahwa potensi risiko UMKM di Kecamatan Undaan berdasar aspek permodalan, produksi dan pemasaran adalah sbb:

Tabel 5. Potensi Risiko UMKM Berdasar Aspek Permodalan, Produksi dan Pemasaran

\begin{tabular}{|r|l|l|l|l|}
\hline No & Variabel Penelitian & Risiko Rendah & Risiko Sedang & Risiko Tinggi \\
\hline 1 & Aspek Permodalan & 8 UMKM & - & 1 UMKM \\
2 & Aspek Produksi & 5 UMKM & 4 UMKM & - \\
3 & ASpek Pemasaran & 8 UMKM & 1 UMKM & - \\
\hline
\end{tabular}

\section{Kriteria Penetapan Peringkat Komposit Potensi Risiko UMKM}

\section{Tabel 6. Kriteria Penetapan Peringkat Komposit Potensi Risiko UMKM}

\begin{tabular}{|r|l|l|l|}
\hline No & Nama Usaha & Skor & Keterangan \\
\hline 1 & MEBEL SUPARNO & 1.17 & Sedang \\
2 & PERTOKOAN & 1.67 & Sedang \\
3 & WARUNG KOPI SUMATNI & 1.00 & Rendah \\
4 & TOKO JAJANAN & 1.00 & Rendah \\
5 & KOPI KUMIATI & 1.33 & Sedang \\
6 & TOKO PERTANIAN ABDULLAH & 1.00 & Rendah \\
7 & JAHIT TAS INDAH & 2.00 & Sedang \\
8 & BENGKEL MOTOR ABUT & 1.00 & Rendah \\
9 & TOKO KUSNO PRANOTO & 1.00 & Rendah \\
\hline
\end{tabular}

Dari hasil penetapan peringkat komposit UMKM pada tabel 5 tampak bahwa potensi risiko UMKM di Kecamatan Undaan adalah 5 UMKM 
mempunyai potensi risiko rendah dan 4 UMKM mempunyai potensi risiko sedang.

\section{PENUTUP}

\section{Kesimpulan}

a. Pengelompokan UMKM segmen kecil dan menengah di Kecamatan Undaan, Kabupaten Kudus, berdasar potensi risiko yang ditinjau dari aspek permodalan, produksi, dan pemasaran hanya terdapat 1 UMKM yang berpotensi risiko tinggi yakni di aspek permodalan.

b. Menghasilkan penetapan peringkat komposit potensi risiko UMKM potensi risiko UMKM di Kecamatan Undaan adalah 5 UMKM mempunyai potensi risiko rendah dan 4 UMKM mempunyai potensi risiko sedang.

\section{Saran}

a. Pembinaan UMKM oleh Disnakerperinkop \& UKM, dan pihak-pihak lain yang berkepentingan dilakukan berdasarkan potensi risiko yang dimiliki masing-masing UMKM.

b. Atas adanya UMKM berpotensi risiko tinggi di aspek permodalan, dapat diberikan penyuluhan untuk peningkatan produktivitas usaha yang diikuti dengan peningkatan omzet dan keuntungan usaha, antara lain dalam hal terciptanya produksi yang efektif dan efisien, perluasan pangsa pasar dan variasi produk sesuai kebutuhan konsumen, dan pembukuan yang baik, sehingga dapat memenuhi kewajiban pengembalian modal ke pihak lembaga keuangan tepat waktu.

c. Pendampingan UMKM berpotensi risiko rendah dan sedang juga harus diperhatikan berdasarkan aspek rsisikonya, sehingga diperoleh mitigasi risiko yang sesuai untuk masing-masing jenis usaha.

\section{DAFTAR PUSTAKA}

Djojosoedarso, S. 1999. Prinsip-Prinsip Manajemen Risiko Dan Asuransi. Salemba Empat, Jakarta.

Harsono, D. Sonni. 1993. Prinsip-Prinsip dan Praktek Asuransi: PK-01. Jakarta Insurance Institute: Yayasan Pengembangan Ilmu Asuransi, Jakarta.

Lam, James. 2003. Enterprise Risk Management: From Incentives To Controls. John Willey \& Sons, Inc., New Jersey.

Artikel/ Jurnal Ilmiah:

Alifiana, Ajeng, Mia. 2008. Analisis Faktor-Faktor Risiko Tertanggung Perusahaan Asuransi Kerugian (Studi Pada PT Asuransi Rama Satria 
Wibawa). Tesis Prodi. Magister Manajemen, Fakultas Ekonomika dan Bisnis, Universitas Gadjah Mada, Yogyakarta.

Sudaryanto. Ragimun. Wijayanti, RR. 2014. Strategi Pemberdayaan UMKM

Menghadapi Pasar Bebas ASEAN, diakses dari http://www.kemenkeu.go.id/sites/default/files/Strategi\%20Pemberdayaan\%20 UMKM.pdf pada tanggal 19 Februari 2016 pukul 19.30 WIB.

Trenggana, MH. Masodah. Pribadi, ME. 2012. Analisis Potensi \& Hambatan Yang Dihadapi UMKM Dalam Mengembangkan Usaha Dengan Menggunakan Alat Bantu Sistem Informasi Geografis (SIG): Studi Kasus Kecamatan Pancoran Mas Kota Depok, diakses dari http://library.gunadarma.ac.id/repository/view/1061/analisis-potensi-danhambatan-yang-dihadapi-umkm-dalam mengembangkan-usaha-denganmenggunakan-alat-bantu-sistem-informasi-geografis-sig-studi-kasuskecamatan-pancoran-mas-kota-depok.html/ pada tgl. 19 Februari 2016 pukul 19.30 WIB.

Wajdi, FM. Setyawan, AA. Syamsudin. Isa, M. 2012. Manajemen Risiko Bisnis UMKM Di Kota Surakarta. Jurnal BENEFIT: Jurnal Manajemen dan Bisnis, Vol. 16, No.2.

\section{Ketentuan, Peraturan Perundang - Undangan:}

Badan Pusat Statistik (BPS), tentang definisi UKM.

Badan Pusat Statistik (BPS), Kabupaten Kudus, tentang Kabupaten Kudus Dalam Angka 2016 (Kudus Regency In Figures), Katalog 1102001.3319.

Kementrian Negara Koperasi dan Usaha Kecil Menengah (Menegkop dan UKM), tentang definisi UMKM.

LPPI, Bank Indonesia, 2015, tentang Profil Bisnis Usaha Mikro, Kecil, dan Menengah (UMKM).

Peraturan Menteri Koperasi dan Usaha Kecil dan Menengah Republik Indonesia No. 07/PER/M.KUKM/VII/2015 tentang Rencana Strategis Kementerian Koperasi dan Usaha Kecil dan Menengah Tahun 2015-2019.

Undang-Undang Republik Indonesia No. 20 Tahun 2008 tentang Usaha Mikro, Kecil dan Menengah. 